\title{
Sugarcane Yellow Leaf Disease in Brazil: Evidence of Association with a Luteovirus
}

Jorge Vega, Department of Plant Physiology, Institute of Biology, Universidade Estadual de Campinas (UNICAMP), C.P. 6109, 13083-970 Campinas, SP, Brazil; Sandra M. M. Scagliusi, Section of Virology, Instituto Agronômico, C.P.28, 13001-001 Campinas, SP, Brazil; and Eugênio C. Ulian, Copersucar Technology Center, C.P. 162, 13400-970 Piracicaba, SP, Brazil

\begin{abstract}
Vega, J., Scagliusi, S. M. M., and Ulian, E. C. 1997. Sugarcane yellow leaf disease in Brazil: Evidence of association with a luteovirus. Plant Dis. 81:21-26.

Evidence of the viral etiology of sugarcane yellow leaf disease (SCYLD), occurring in southeast Brazil, was obtained by light and electron microscopy combined with serology. Light microscopy using epifluorescence illumination showed an abnormal yellow-green fluorescing material in the phloem of SCYLD-affected plants that was rarely observed in control plants. Immunolocalization in tissue-printed (or -blotted) nitrocellulose membranes, using barley yellow dwarf virus (BYDV) serotype PAV antiserum, showed a weak but clearly positive reaction in the phloem. Isometric viruslike particles of 24 to $26 \mathrm{~nm}$ in diameter were found by electron microscopy both in situ and in partially purified preparations. Examination of thin sections showed that phloem companion cells contained viruslike particles and presented cytological changes apparently related to the development of virus infection. Partially purified preparations produced UV absorption spectra typical of a nucleoprotein, with high absorbance at $260 \mathrm{~nm}$, as expected for isometric virus particles. Virus particles were observed in extracts and partially purified preparations using immunosorbent electron microscopy with BYDV-PAV antiserum. Plate-trapped antigen enzyme-linked immunosorbent assays with the same antiserum indicate a weak serological relationship between BYDV-PAV and SCYLD-associated virus.
\end{abstract}

Additional keywords: autofluorescence, phloem-limited virus, tissue-printing immunohistochemistry

Severe leaf yellowing symptoms have been observed since 1990 to 1991 in sugarcane-producing areas of southeast Brazil, mainly in the state of São Paulo. In 1992, this anomaly, called sugarcane yellow leaf disease (SCYLD), was widespread in the variety SP 71-6163. Although symptoms were most severe in the widely cultivated variety SP 71-6163, typical SCYLD symptoms also appeared in other varieties.

Symptoms in SP 71-6163 are not visible in the youngest two or three leaves, becoming evident only in mature leaves. The first symptom is the intense yellowing of the midrib, which appears on the abaxial surface. Older leaves (sixth or seventh from the growing tip) show a red coloration on the adaxial surface of the midrib. Discoloration subsequently spreads to the leaf blade, proceeding from the tip toward the base of the leaf, and is followed eventually by tissue necrosis. Roots and stalks show impaired growth, and production is significantly reduced. Similar symptoms

Corresponding author: J. Vega

E-mail: jvega@turing.unicamp.br

Fax: 55-19-239 3124

Accepted for publication 4 September 1996

Publication no. D-1996-1112-04R

(C) 1997 The American Phytopathological Society have been described for some varieties in Hawaii (13), Australia (1), and other sugarcane-producing countries.

The variety SP 71-6163, which is very sensitive to SCYLD, is highly favored by sugarcane planters because of its elevated sucrose content and good mass production. In 1993, this variety represented $25 \%$ of the sugarcane cultivated in the state of São Paulo. The importance of the problem caused by SCYLD can be appreciated if one considers that in the whole of Brazil, the variety SP 71-6163 was planted in about 750,000 ha. Nearly $70 \%$ of this area was located in São Paulo, where SCYLD was present in almost all planted areas.

In this paper, we present evidence, obtained by electron microscopy of tissues and partially purified virus particles, that SCYLD is associated with virus infection. At the light microscope level, we report results of immunolocalization and autofluorescence observations. Some of these results were objects of preliminary communications (14-16).

\section{MATERIALS AND METHODS}

Plant material and immunoreagents. Field samples of sugarcane with SCYLD symptoms of varying severity or without symptoms were collected, stored in plastic bags at $4^{\circ} \mathrm{C}$, and processed within 7 days. As controls, sugarcane seedlings of differ- ent varieties were grown in an aphid-protected greenhouse. Rabbit antisera to barley yellow dwarf virus (BYDV) serotypes PAV, MAV, and RPV were kindly provided by Stewart M. Gray (USDA-ARS, Department of Plant Pathology, Cornell University, Ithaca, NY).

Fluorescence microscopy. Fresh sections cut from midribs, leaf sheaths, and stalks with a new razor blade were mounted in a drop of distilled water on a microscope slide, covered with a standard coverslip, and observed under a light microscope (Jenalumar-Contrast, Carl Zeiss, Jena, Germany). The general anatomy was examined with transmitted white light followed by autofluorescence with blue light by epi-illumination. Examination by epifluorescence with blue excitation light was carried out through a dichroic splitter at $510 \mathrm{~nm}$ and a yellow barrier filter (G247) with a cutoff at $510 \mathrm{~nm}$. Photomicrographs were obtained with a $35-\mathrm{mm}$ film camera system (Carl Zeiss, Jena) using color and black-and-white film.

Tissue-printing immunohistochemistry. This procedure is similar to the tissueblotting method used by Lin et al. (9), with some modifications. Fresh cross-sectioned leaf midribs, leaf sheaths, and stalks were applied directly onto nitrocellulose membranes, but instead of simply blotting the membrane, the sections were "printed." By printing, we mean that the fresh sectioned surface is pressed onto the membrane, leaving a bas-relief replica in the membrane surface. After printing, the membrane was processed for the immunological localization of virus: blocked $1 \mathrm{~h}$ with $2 \%$ bovine serum albumin (Sigma) in $0.05 \mathrm{M}$ Tris- $\mathrm{HCl}$ buffer, $\mathrm{pH} 7.5$, then treated $1 \mathrm{~h}$ with 1:1,000 antiserum BYDV-PAV in the same buffer and $1 \mathrm{~h}$ with goat IgG-antirabbit IgG conjugated with alkaline phosphatase (Sigma 8025) diluted 1:5,000 in Tris- $\mathrm{HCl}$ buffer. Between steps, the membranes were thoroughly washed in Tris$\mathrm{HCl}$ buffer containing $0.8 \% \mathrm{NaCl}$ and $0.5 \%$ Tween-20. Finally, the alkaline phosphatase substrate (nitro blue tetrazolium at $165 \mu \mathrm{g} / \mathrm{ml}$ and 5-bromo-4-chloro-3-indolyl phosphate at $85 \mu \mathrm{g} / \mathrm{ml}$ in $0.1 \mathrm{M}$ Tris- $\mathrm{HCl}$, $\mathrm{pH} 9.5$, containing $0.8 \% \mathrm{NaCl}$ and $5 \mathrm{mM}$ $\mathrm{MgCl}$ ) was added and incubated for 15 to $25 \mathrm{~min}$. The alkaline phosphatase reaction was stopped by washing thoroughly in Tris- $\mathrm{HCl}$ buffer containing $5 \mathrm{mM}$ EDTA 
and in distilled water. After air-drying, the membrane was examined and photographed in the light microscope with transmitted white light at 30- to 100-fold magnification.

Electron microscopy of thin sections of tissues. Fragments of $1 \mathrm{~mm}^{3}$ taken from the leaf blade, midrib, sheath, and stalk were double fixed, first in a mixture of glutaraldehyde $(2.5 \%)$ and depolymerized paraformaldehyde (4\%) in $0.1 \mathrm{M}$ cacodylate buffer, $\mathrm{pH} 7.2(8)$, for 2 to $6 \mathrm{~h}$ at $10^{\circ} \mathrm{C}$ under mild vacuum during the first hour. The samples, previously washed in cacodylate buffer containing 3\% sucrose, received the second fixation in $1 \% \mathrm{OsO}_{4}$ in cacodylate buffer containing $1.5 \%$ sucrose for $6 \mathrm{~h}$, or overnight, at $4^{\circ} \mathrm{C}$. After thorough washing, the samples were stained in bloc with $2 \%$ uranyl acetate in $0.1 \mathrm{M}$ maleate buffer, $\mathrm{pH} 6.5$, for $4 \mathrm{~h}$, washed thoroughly in distilled water, dehydrated with dimethoxipropane and acetone, and embedded in Epon or an Epon-Araldite mixture (10). Ultrathin sections, mounted in Parlodion-carbon coated grids, were stained with lead citrate (17) and observed in a Zeiss EM-10C electron microscope.

Virus purification. The purification procedure was similar to the method used by Hammond et al. (6) for BYDV. Infected leaves, transversely cut in pieces of about 1 $\mathrm{cm}$, were frozen in liquid nitrogen and pulverized with a pestle. The powder was extracted in $0.5 \mathrm{M}$ potassium phosphate buffer, $\mathrm{pH}$ 6.0, containing $0.5 \%$ sodium sulfite, $10 \mathrm{mM}$ sodium diethyldithiocarbamate (DIECA), and 2\% Extractase for 3 to $5 \mathrm{~h}$ at 5 to $8^{\circ} \mathrm{C}$ with occasional stirring. After $1 \%$ Triton was added and the mixture
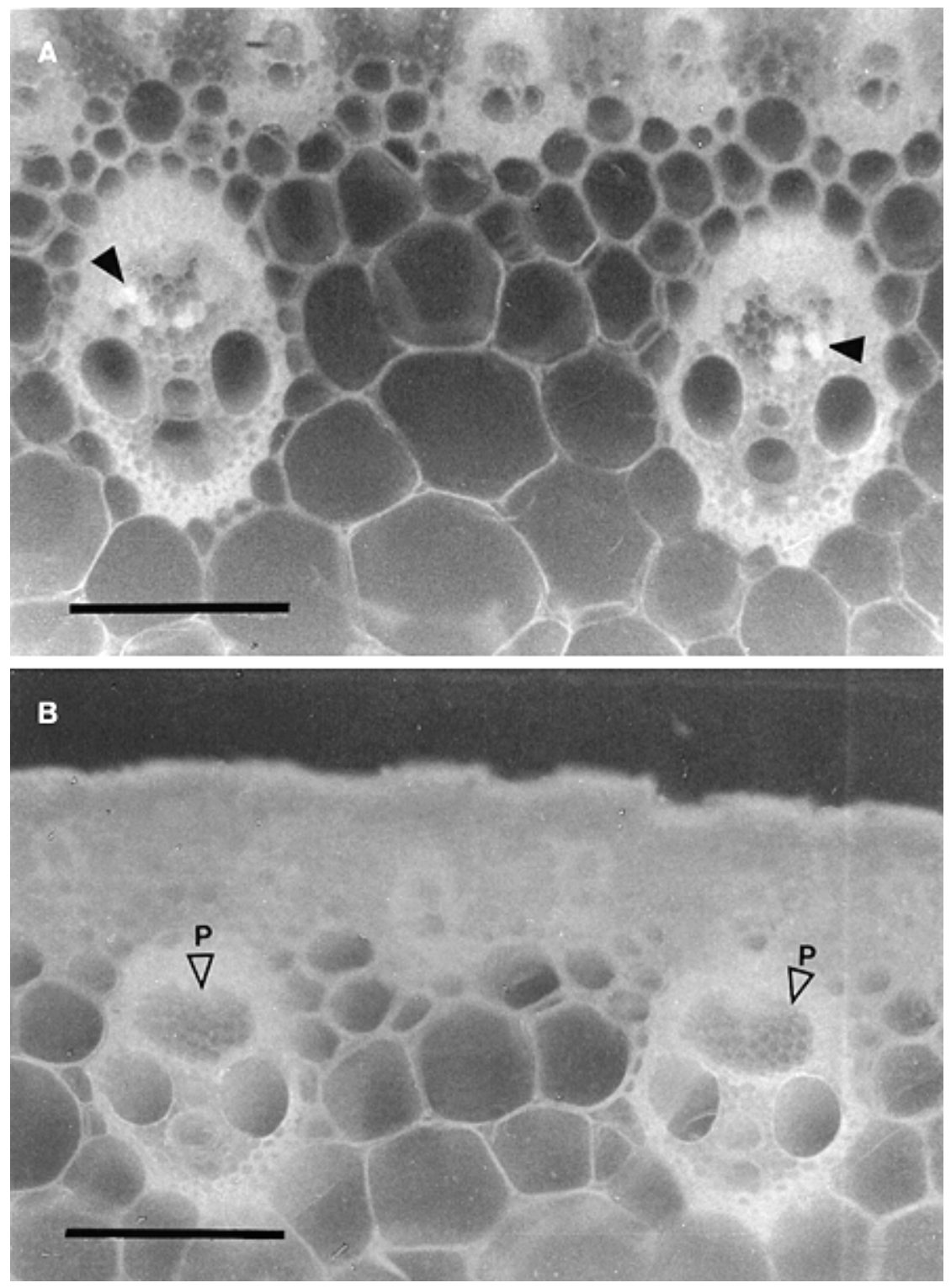

Fig. 1. Vascular bundles of leaf midrib examined by fluorescence microscopy. (A) Yellow-green fluorescing material (arrowheads) in the phloem of SP 71-6163 sugarcane plants with symptoms of sugarcane yellow leaf disease. (B) Symptom-free sugarcane plants showing normal phloem (p). Reference bar $=200 \mu \mathrm{m}$.

was stirred for $30 \mathrm{~min}$, it was filtered through cheesecloth and clarified by adding a $1 / 5$ volume of chloroform- $n$-amyl alcohol mixture (2:1) and stirred $30 \mathrm{~min}$. The mixture was centrifuged at $8,000 \mathrm{rpm}$ for $10 \mathrm{~min}$ (rotor JA14), the aqueous fraction was collected, and $\mathrm{NaCl}(0.25 \mathrm{M}$ final concentration) and PEG (polyethylene glycol MW 8,000, 10\% final concentration) were added. After being stirred 90 min in a cold room, the extract was centrifuged $20 \mathrm{~min}$ at $8,000 \mathrm{rpm}$ (rotor JA14). The pellet was resuspended in $0.1 \mathrm{M}$ phosphate buffer, $\mathrm{pH} 7.0$, and left for $90 \mathrm{~min}$ or overnight before centrifugation for $10 \mathrm{~min}$ at 5,000 rpm (rotor JA20). The supernatant was layered over a $30 \%$ sucrose pad and centrifuged for $3 \mathrm{~h}$ at 33,000 rpm in a type 40 rotor. Pellets were resuspended, centrifuged $5 \mathrm{~min}$ at 7,500 rpm (rotor Ti40), layered over a sucrose gradient obtained by freezing and thawing $4 \mathrm{ml}$ of a $25 \%$ (wt/vol) solution of sucrose in phosphate buffer in a centrifuge tube, and centrifuged for $1 \mathrm{~h}$ at 43,000 rpm in a SW65 rotor. All rotors used were obtained from Beckman Instruments, Inc., Palo Alto, California. Each gradient was fractionated in $0.5-\mathrm{ml}$ aliquots, scanned in UV using a Hitachi U2000 spectrophotometer, examined in the electron microscope, and tested by immunosorbent electron microscopy (ISEM) using BYDV antiserum.

ISEM. ISEM was used to monitor the presence of virus in leaf extracts and in samples taken at various stages of virus purification. The ISEM procedure was essentially as described by Derrick and Brlansky (2). Briefly, electron microscope grids with Parlodion-carbon film were coated with antibodies by floating in antiserum for BYDV (types PAV, MAV, or RPV) diluted $1: 1,000$ in $0.06 \mathrm{M}$ potassium phosphate buffer, $\mathrm{pH} \mathrm{7.2,} \mathrm{for} 1 \mathrm{~h}$ at room temperature. Then the grids were washed in the same buffer and incubated, in a drop of extract or sample of the purification process, in a moist chamber for $2 \mathrm{~h}$ at room temperature or overnight at $4^{\circ} \mathrm{C}$. Finally, the grids were washed thoroughly with distilled water, negatively stained with aqueous $2 \%$ uranyl acetate, and examined under the electron microscope.

Enzyme-linked immunosorbent assay (ELISA). The indirect plate-trapped antigen (PTA) ELISA, used in attempts to detect virus in leaf extracts or purification fractions, was as described by Mowat and Dawson (11). Leaf extracts (1:10 wt/vol) or 1:100 dilutions of gradient fractions prepared in $0.1 \mathrm{M}$ carbonate buffer, $\mathrm{pH} 9.5$, were used as first plate coating, followed by crude antiserum (diluted 1:1,000 in 0.05 $\mathrm{M}$ phosphate buffer, $\mathrm{pH}$ 7.2) and anti-rabbit IgG goat IgG conjugated with alkaline phosphatase (Sigma A-8025) (1:9,000 dilution in phosphate buffer). The plates were incubated at $37^{\circ} \mathrm{C}$ for $1 \mathrm{~h}$ in each step, with three washings with $0.05 \mathrm{M}$ phosphate buffer, $\mathrm{pH} 7.2$, containing $0.8 \%$ 
$\mathrm{NaCl}$ and $0.05 \%$ Tween-20, between steps. Finally, $50 \mu \mathrm{l}$ of substrate ( $p$-nitrophenyl phosphate at $0.6 \mathrm{mg} / \mathrm{ml}$ in triethanolamine buffer) was added, and color development was monitored in a Biotek EL307 plate reader at $405 \mathrm{~nm}$ after incubation for $2 \mathrm{~h}$ at room temperature, or overnight at $4^{\circ} \mathrm{C}$.

\section{RESULTS}

Fluorescence light microscopy. The examination of sections from plants with symptoms of SCYLD by the epifluorescence method revealed numerous vascular bundles with yellow-green fluorescing material within the phloem cells (Fig. 1A). In plants not expressing symptoms, the vascular bundles rarely presented fluorescence in the phloem (Fig. 1B). In some sections, the fluorescing cells of the phloem appeared to be stained dark brown when observed by transmitted white light (micrographs not shown). Sections from symptom-free sugarcane showed the normal yellow-green fluorescence of secondary cell walls (Fig. 1B). This fluorescence was evident in fiber cells, which form a strong sheath around the vascular bundle, and in xylem vessel elements inside the bundle. The phloem was the darkest tissue in the vascular bundle, because its primary thin cell walls presented mild green fluorescence. The cell content of normal phloem cells did not show fluorescence.

Tissue-printing immunohistochemistry. Freshly sectioned surfaces of leaves and stalks, when applied to membranes with pressure, produced bas-relief replicas of the tissues on the surface of the nitrocellulose membrane. This method rendered good results, showing fine histological details with sugarcane, which has many hard tissues (mainly fibers). Immunological reaction with antiserum for BYDV-PAV produced precipitates of 30 to $40 \mu \mathrm{m}$, typical of a positive reaction, clearly visible by transmitted light microscopy (transparency) (Fig. 2). This method of observation revealed histological details present in the replica, allowing the visualization of the precipitates over the phloem. These results were observed in vascular bundles of leaf midribs, leaf sheaths, and stalks (Fig. 2). No precipitates were observed in other tissues of infected samples or in control healthy sugarcane seedlings growing in the greenhouse.

Electron microscopy of tissues. Viruslike particles were found forming amorphous aggregates in the cytoplasm of companion cells of the phloem. In most samples, the companion cells containing viruslike particles had apparently normal nuclei, and the only cytopathic change noted was the presence of rounded masses of fibrillar material in the cytoplasm (Fig. 3A compared with 3B). Viruslike particles were recognized by their sharp circular outlines, high electron opacity, and diameter of 22 to $24 \mathrm{~nm}$, which distinguish them from ribosomes (measuring 18 to $20 \mathrm{~nm}$ ).
The putative virus particles appeared to be restricted to companion cells, since they were not observed in other tissues or even in other types of phloem cells. Within companion cells, particles were only seen in the cytoplasm; they were not found in the nucleus or in other cytoplasmic organelles. In some samples from plants with SCYLD, cytopathic alterations in the phloem companion cells were observed: the nucleus contained masses of electrondense material and the nuclear envelope was disintegrated (Fig. 3C), or appeared contracted, with densely stained heterochromatin (Fig. 3D). Cytoplasm contained numerous vesicles (Fig. 3C) or was highly electron opaque and formed vesicles protruding into the vacuole (Fig. 3D). However, virus particles were not clearly identified in cells with these cytopathic changes.

Serology. ISEM tests with sugarcane extracts using BYDV antiserum showed some viruslike polyhedral particles of 24 to $26 \mathrm{~nm}$, but in such low quantities that it was difficult to differentiate infected from healthy samples (Fig. 4A). To overcome this limitation, the samples were subjected to a virus semipurification procedure. Samples of $2 \mathrm{~g}$ of leaf tissue were pulverized in liquid nitrogen; extracted in potassium phosphate buffer containing Extractase, DIECA, and sodium sulfite; clarified; and finally precipitated with PEG, as in the purification method. The pellet was resuspended and centrifuged at low speed, and the supernatant was used in ISEM tests. This procedure allowed the observation of abundant virus particles with the electron microscope (Fig 4B). Comparisons between the three available antisera for the serotypes PAV, MAV, and RPV showed more particles with PAV antiserum. Based on these results, later tests were done using only the PAV-BYDV-AS. No particles were observed in samples from healthy sugarcane seedlings kept in the greenhouse.

Attempts to demonstrate a reaction of the SCYLD-associated virus with BYDV antiserum in PTA-ELISA were not conclusive. Absorbance values of samples from plants with SCYLD (mean $A_{405}=0.230$ ) were higher, in two independent tests, than the healthy ones (mean $A_{405}=0.165$ ). However, the difference between infected and healthy samples could not be considered significant, since the criterion generally used in PTA-ELISA is that absorbance values of infected samples must be at least twice that of the healthy ones (11). PTAELISA with BYDV-AS gave a significant signal when used in testing the fractions from the density gradient. The second fraction from the top of the gradient, corresponding to the electron micrograph shown in Figure 4C and scanned in UV (Fig. 5),
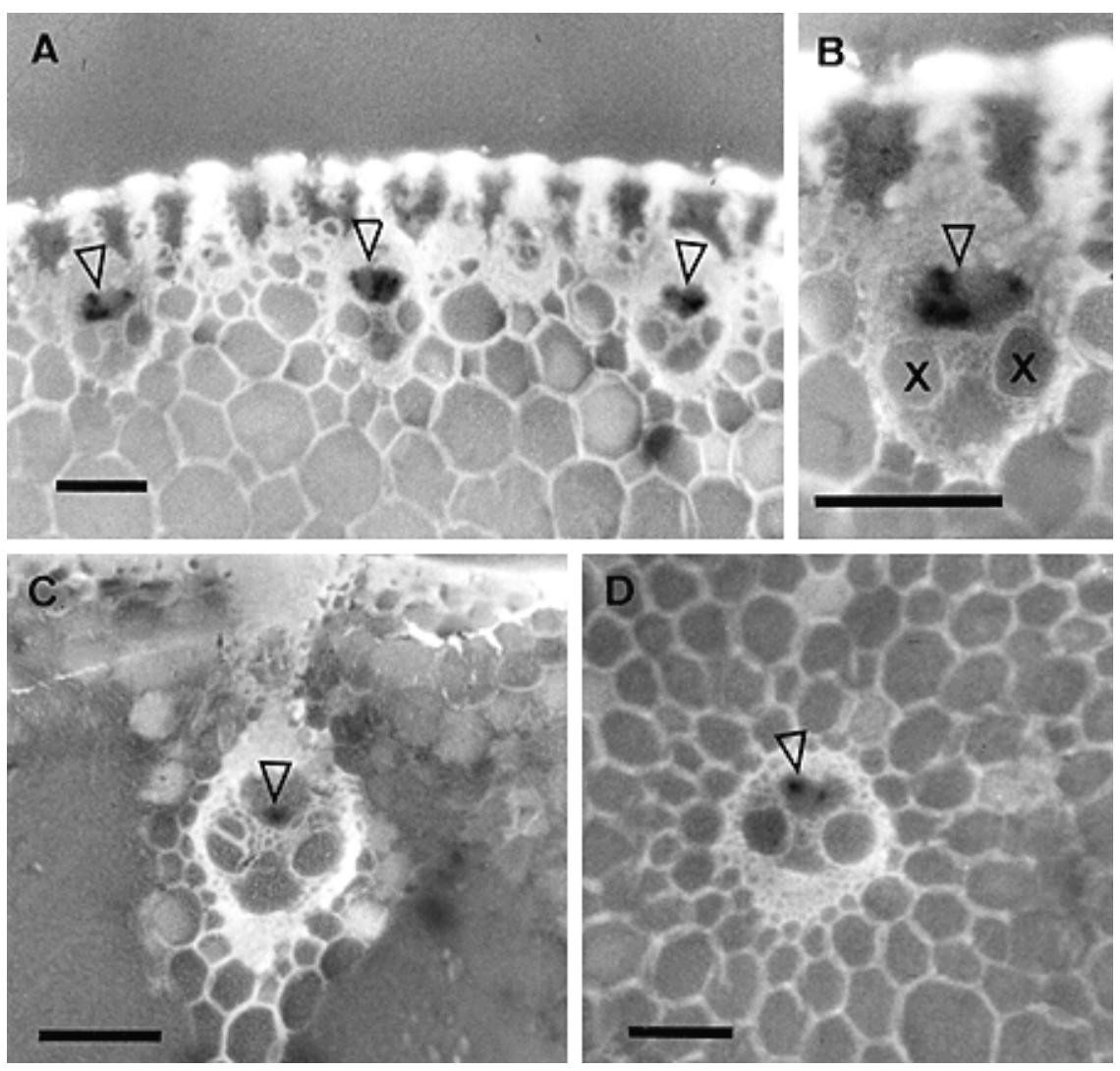

Fig. 2. Light micrographs of nitrocellulose membranes processed by tissue printing and immunolocalization of antigens reacting with barley yellow dwarf virus serotype PAV antiserum. Precipitates (arrowheads) appear in the phloem in (A and B) leaf midribs, (C) leaf sheath, and (D) stalks. Reference bar $=200 \mu \mathrm{m}$. 

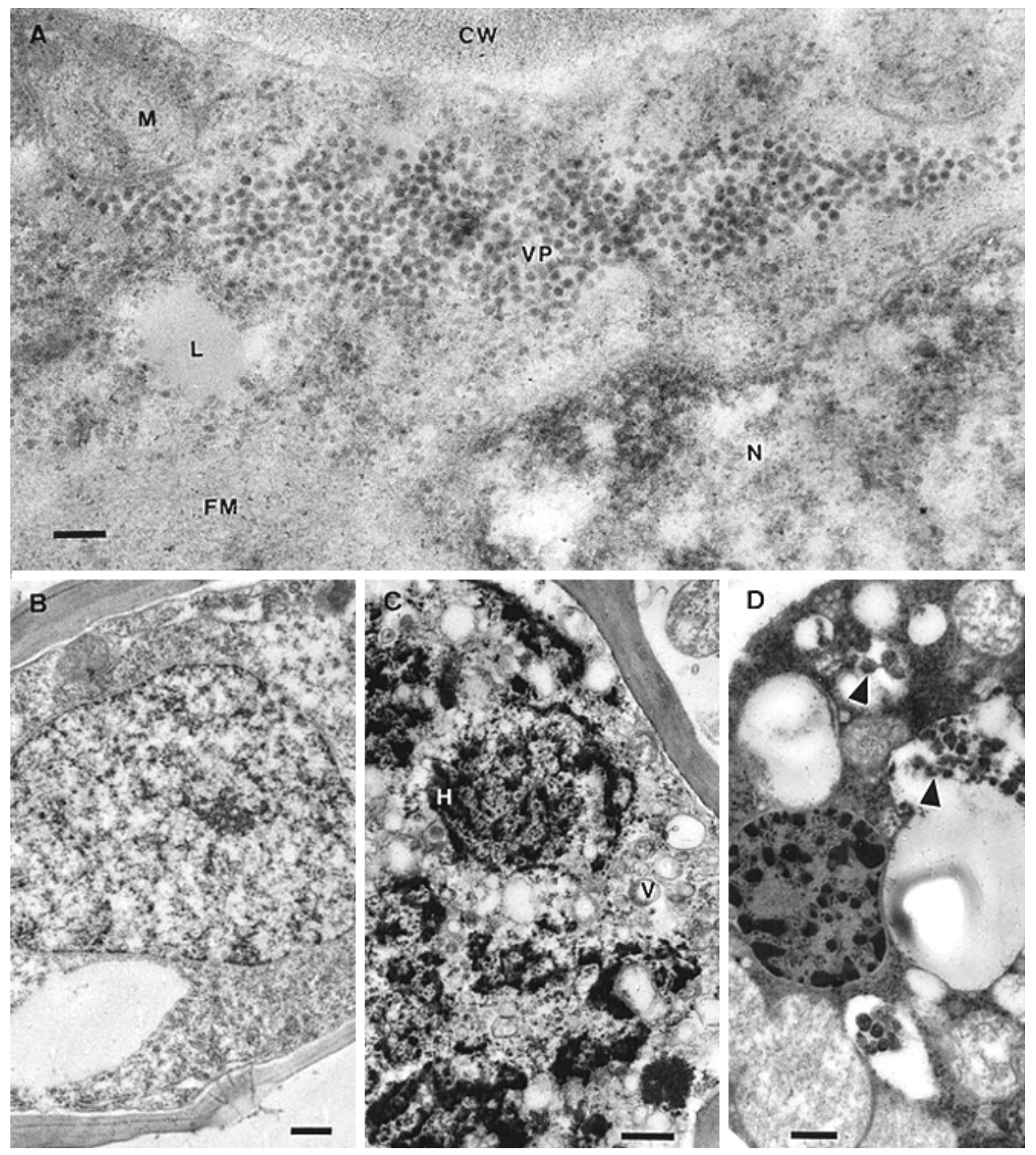

Fig 3. Electron micrographs of ultrathin sections of sugarcane phloem companion cells. (A) Virus particles (VP) in the cytoplasm showing a lipid droplet (L) and accumulation of a finely fibrillar material (FM). CW: cell wall, N: nucleus, and M: mitochondria. Reference bar $=100 \mathrm{~nm}$. (B) Normal companion cell from symptom-free sugarcane. (C and D) Samples from plants with sugarcane yellow leaf disease symptoms. (C) Cell showing broken nuclear envelope and increased dense heterochromatin $(\mathrm{H})$, while numerous membrane-limited vesicles (V) appear in the cytoplasm. (D) Condensed nucleus and cytoplasm observed in some companion cells. Cytoplasm may be seen protruding into the vacuole (arrowheads). Reference bar $=500 \mathrm{~nm}$ in B through D.

gave an $A_{405}$ value of 0.270 , which was about three times greater than that in a middle fraction of the gradient $\left(A_{405}=\right.$ 0.080).

Virus purification. After density gradient centrifugation, the top three fractions showed numerous isometric virus particles with diameters of about 24 to $26 \mathrm{~nm}$ when examined by ISEM (Fig. 4C). The UV absorbance spectrum of these top fractions presented a maximum at $260 \mathrm{~nm}$ (Fig. 5). The purification experiment was repeated three times with identical results.

\section{DISCUSSION}

The autofluorescence observed in the phloem of sugarcane plants with yellow leaf symptoms is similar to that described in different species associated with infection by phloem-limited pathogens such as luteoviruses, closteroviruses, and mycoplasmalike organisms (12). The fluorescence is interpreted as evidence of accumulation of phenolic compounds in the phloem, which may occur in any cell where compartmentalization is lost as a consequence of membrane damage (7). This means that the appearance of autofluorescence should not be considered a specific histopathological symptom, but 

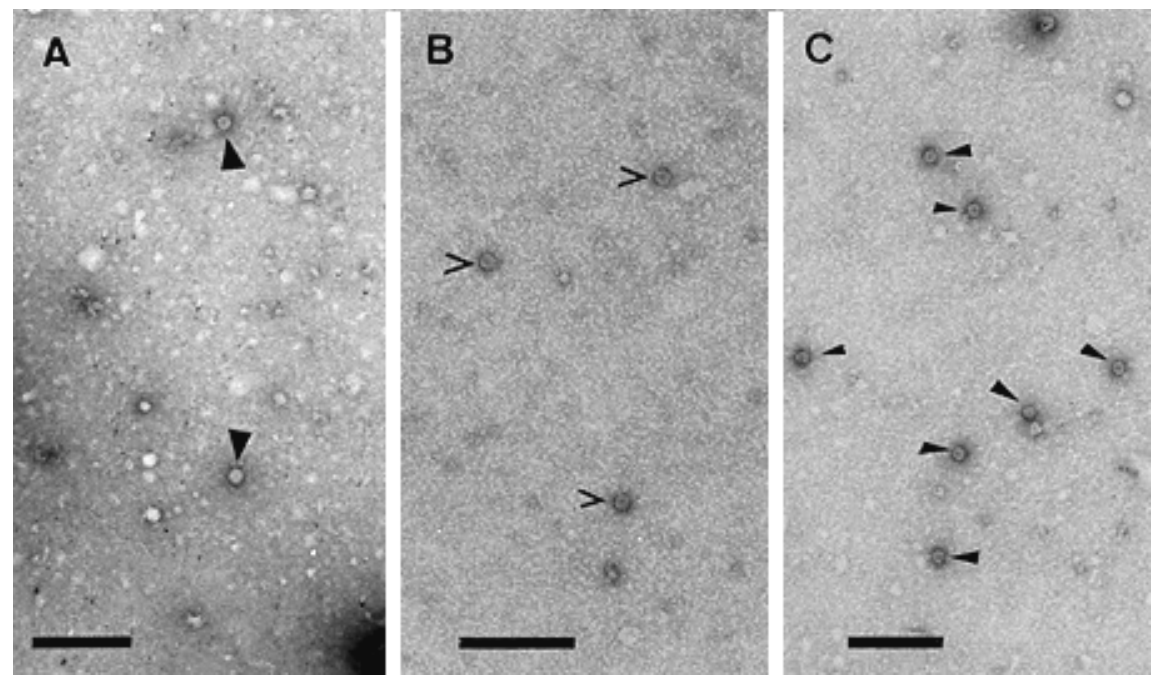

Fig. 4. Electron micrographs of virus particles observed in immunosorbent electron microscopy tests using barley yellow dwarf virus serotype PAV antiserum, with different types of sample processing. (A) Crude extract of sugarcane yellow leaf disease-affected sugarcane. (B) Sample processed for virus concentration by PEG precipitation. (C) Purified preparation after density gradient centrifugation. Reference bar $=200 \mathrm{~nm}$.

indicates some kind of dysfunction of the phloem, which leads to accumulation of phenolics. The cause of this dysfunction may be pathological or physiological, for example, aging or nutritional imbalances. These concepts may help to explain the observation of fluorescence in phloem of healthy plants, although in much fewer vascular bundles than in plants with SCYLD. In healthy plants, fluorescence may be caused by disorganization and death of phloem cells as part of a physiological process probably related to environmental stress response. The presence of a yellow-fluorescing material in the phloem in most vascular bundles of samples with SCYLD is an indication that the disease is related to a phloem dysfunction, but it does not itself prove the presence of a pathogenic agent in this tissue.

Immunohistochemical tissue printing gave more direct evidence of the presence of a virus in the phloem. This technique allows the visualization of antibodies to BYDV-PAV reacting with an antigen located in the phloem. This fact, together with the increase of autofluorescence in the phloem of plants with SCYLD, greatly strengthens the hypothesis that a virus is involved in the etiology of SCYLD.

The results of immunohistochemical tissue printing suggest some serological relationship between BYDV and SCYLDassociated virus (SCYLaV). However, the small size of the precipitates, which were only visible under a microscope, may suggest a weak affinity between the virus and the antibodies used. This interpretation is also consistent with results obtained using ELISA.

The visualization of polyhedral viruslike particles in the cytoplasm of phloem companion cells is good evidence that the virus detected is probably a luteovirus. The cytopathology of sugarcane yellow leaf associated virus, however, showed several differences from the cytopathology reported for BYDV in oat (3). One difference refers to cellular location of SCYLaV particles: ion cells, whereas BYDV particles appear in the sieve tube elements and parenchyma cells as well. Also, intracellular distribution of particles seems to differ: particles of BYDV appear in the nucleus in all isolates described, whereas SCYLaV particles were not found in the nucleus, appearing only in the cytoplasm. Another ultrastructural cell alteration described for BYDV is the association of virus particles with filaments (5), which was not observed in sugarcane with SCYLaV. For a precise comparison, it should be taken into consideration that reported studies (4) were done on early infections of BYDV, focusing on the differentiation process of phloem cells. Our results are based on samples from field-grown plants, without any possibility of correlation to the age of infection. As the samples were taken from sugarcane plants with symptoms, it is presumed that the infection was at an advanced stage, since newly propagated infected plants take a long time to produce symptoms. A meticulous study of the development of the infection will only be possible when knowledge about the transmission of SCYLaV is available.

The purification of SCYLaV had limited success, since the concentration of virus particles was not high enough for antiserum production. However, such tests allowed the determination of the presence of virus particles in SCYLD-affected plants by a method differing from in situ examination by electron microscopy or detection they were found only in phloem compan-

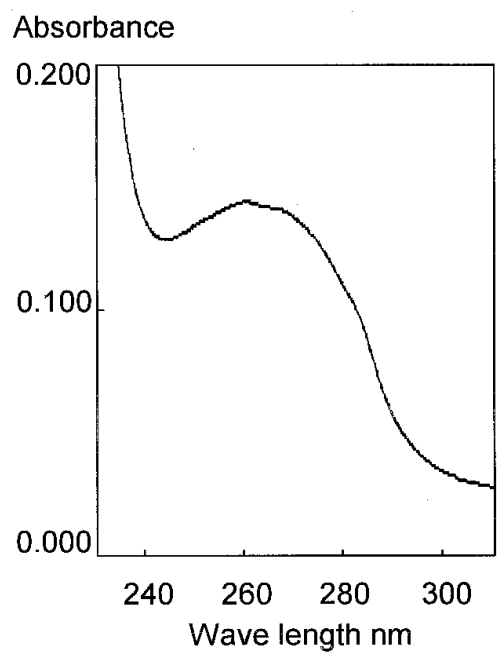

Fig. 5. Absorbance spectrum of fraction $n^{\circ} 2$ from the top of a sucrose gradient containing virus particles as revealed by examination under the electron microscope. Observe the peak at $260 \mathrm{~nm}$, characteristic of the presence of a nucleoprotein.

by a serological procedure. It should be noted that purification was repeated successfully, giving a good degree of confidence with this result. Diluted preparations of virus particles obtained from density gradient centrifugation have a UV absorption spectrum with a typical shoulder, showing a peak at $260 \mathrm{~nm}$, characteristic of a nucleoprotein. Since it was evident in a poorly purified preparation, it is indicative of high specific absorbance of the virus, as expected for a polyhedral virus.

The data demonstrate the association of an isometric virus, which meets several characteristics of a luteovirus, with SCYLD. Work is in progress to further characterize this virus, develop diagnostic procedures, and identify its mode of transmission.

\section{ACKNOWLEDGMENTS}

Research supported by FAPESP (Fundação de Amparo à Pesquisa do Estado de São Paulo), Brazil, by a grant conferred to J. Vega. Additional funding was provided by Copersucar (Cooperativa de Produtores de Açúcar e de Álcool do Estado de São Paulo). We thank Stewart M. Gray, USDAARS, Department of Plant Pathology, Cornell University, Ithaca, NY, for kindly providing BYDV antisera and Ladaslav Sodek, DPP-IB, UNICAMP, for critical review of the manuscript.

\section{LITERATURE CITED}

1. Anonymous. 1994. Yellow leaf syndrome may be in Australia. BSES (Brisbane Sugar Experimental Station) Bull. 48:14-15.

2. Derrick, K. S., and Brlansky, R. H. 1976 Assay for viruses and mycoplasmas using serologically specific electron microscopy. Phytopathology 66:815-820.

3. Gill, C. C., and Chong, J. 1975. Development of the infection in oat leaves inoculated with barley yellow dwarf virus. Virology 66:440453.

4. Gill, C. C., and Chong, J. 1976. Differences in cellular ultrastructural alterations between variants of barley yellow dwarf virus. Virology 75:33-47. 
5. Gill, C. C., and Chong, J. 1979. Cytopathological evidence for the division of barley yellow dwarf virus isolates in two subgroups. Virology 95:59-69.

6. Hammond, J., Lister, R. M., and Foster, J. E. 1983. Purification, identity and some properties of an isolate of barley yellow dwarf virus from Indiana. J. Gen. Virol. 64:667-676.

7. Harding, R. M., and Teakle, D. S. 1988. Autofluorescence of necrotic phloem cells and laticifers, and reduced latex flow: New symptoms for papaw dieback disease in Australia. Aust. J. Agric. Res. 39:857-862.

8. Karnovsky, M. J. 1965. A formula of glutaraldehyde fixative of high osmolality for use in electron microscopy. J. Cell Biol. 27:137A

9. Lin, N. S., Hsu, Y. H., and Hsu, H. T. 1990.
Immunological detection of plant viruses and a mycoplasmalike organism by direct tissue blotting on nitrocellulose membranes. Phytopathology 80:824-828.

10. Mollenhauer, H. H. 1964. Plastic embedding mixtures for use in electron microscopy. Stain Technol. 39:111-114.

11. Mowat, W. P., and Dawson, S. 1987. Detection of plant viruses by ELISA using crude sap extracts and unfractionated antisera. J. Virol. Meth. 15:233-247.

12. Namba, S., Yamashita, S., Doi, Y., and Yora, K. 1981. Direct fluorescence detection method (DFD method) for diagnosing yellow type virus diseases and mycoplasma diseases of plants. Ann. Phytopathol. Soc. Jpn. 47:258263.
13. Schenck, S., and Hu, J. S. 1991. Update on the cause of sugarcane yellowleaf syndrome. Pages 45-46 in: Proc. Hawaiian Sugar Technol.

14. Vega, J. 1994. Sugarcane leaf yellowing syndrome: Evidence of association with virus. Summa Phytopathol. 20:50.

15. Vega, J. 1994. Sugarcane leaf yellowing: New evidence of association with a luteovirus. Fitopatol. Bras. 19:322.

16. Vega, J., and Scagliusi, S. M. M. 1994. Sugarcane leaf yellowing: In situ visualization of luteovirus-like particles in phloem cells by electron microscopy. Fitopatol. Bras. 19:330.

17. Venable, J., and Coggeshall, R. 1965. The use of a simple lead citrate stain in electron microscopy. J. Cell Biol. 25:407-408. 